\title{
TAHSP:-
}

The Internet Joưnal of Allied Health Sciences and Practice

A Peer Reviewed Publication of the College of Health Care Sciences at Nova Southeastern University

Dedicated to allied health professional practice and education

http://ijahsp.nova.edu Vol. 12 No. 3 ISSN 1540-580X

\section{The Walking Interview: An Ethnographic Approach to Understanding Disability}

\author{
Mary Butler, BScOT, MA, PhD 1 \\ Sarah Derrett, BA, MPH, PhD²
}

1. Senior Lecturer, School of Occupational Therapy, Otago Polytechnic Dunedin, New Zealand

2. Associate Professor, IPRU, Department of Preventive and Social Medicine, University of Otago Dunedin, New Zealand

New Zealand

CITATION: Butler M, Derrett S. The Walking Interview: An Ethnographic Approach to Understanding Disability. The Internet Journal of Allied Health Sciences and Practice. July 2014. Volume 12 Number 3.

\section{ABSTRACT}

The purpose of this paper is to describe a method of interviewing where walking is explicitly the focus. The interviews were one element of a qualitative study, which was part of a multi-method prospective outcomes of injury study. Four participants were purposively chosen for follow up because they had an injury following a pre-existing disability. The results of this study indicate walking as a method of interviewing has the capacity to add depth and richness to the kind of information obtained. The process of walking lends itself a range of affordances, including shifting the power balance implicit in the research relationship; situated cognition describing being in place and time; performativity; and the way that the disabled body is rendered visible through this embodied process. In conclusion, the potential for engaging in activity as a method has not been explored outside of ethnography. It is suggested that this form of interviewing has particular resonance in understanding the world view of people with disability. It is a particularly appropriate method to apply in occupational therapy, which has activity as a prime focus of therapeutic engagement.

\section{INTRODUCTION}

This paper is a reflection on the use of walking as an interview method. It describes the experience of four people with pre-injury disability. These were a small sample from a mixed method study, which took place in New Zealand between 2007 and 20111. The study is situated in the narrow space between disability studies and medical anthropology and it describes walking as an ethnographic method that can add an embodied understanding of the experience of disability.

Ethnography is a qualitative research design aimed at exploring cultural phenomena. Data collection methods are meant to capture the meanings of ordinary activities as they occur in natural settings. Participant observation is one among many methods of data collection within ethnography. The question of how much any particular research project tends towards participation or observation is a lively one in qualitative research. ${ }^{2}$ In this paper, a study is described that commenced with a low level of participation, the traditional sedentary interview, and developed a strategy involving higher levels of participation, the walking interview. Each strategy offers a particular way of seeing and particular perspective on what is observed and how it might be analysed and presented.

In methodological terms, the awareness of mobility as a paradigm has led to research that is taken out of fixed environments and introduces a range of new issues to consider. ${ }^{3}$ The idea that walking with others creates the capacity for additional insights has long been understood in participant observation. Some of the best known classical accounts of how ethnographers found acceptance in a community involve walking or running with research participants. In recent work, Carpiano has described the "go-along" as a hybrid form of interview and participant observation. ${ }^{4,5}$ This has parallels with "shadowing" used in organisational 
research where researchers follow their subjects around, ${ }^{3}$ or "bimbles", where the interviewer gently removes the participant away from a field of confrontation in a "meandering walk with no particular haste or purpose."

Interestingly, there has been little work done on using mobility as a research modality with people who have disability. One exception is Andrew Irving in an essay called: "Life made strange: an Essay on the Re-inhabitation of Bodies and Landscapes". He described how prior to walking with a participant (Frances) his awareness of the experience of AIDS had been based upon "the stasis of his living room". Francis was able to chat easily as long as he was sitting in his shabby chair. This changed when Irving took him outside to walk:

...where Francis' every step seemed present to consciousness and where few words were exchanged even when resting' (p.325). ${ }^{7}$

He described this process as 'walking fieldwork' and it became for Irving a way of understanding the experience of living with AIDS. It forced him to recognise the otherness of Francis' lived experience, particularly in the slow pace that unintentionally communicated an altered experience of time and space. Walking fieldwork, in the words of Irving, is:

an ethnographic tactic whereby I accompanied people moving between places and witnessed those moments when their bodies - or the surrounding world - became 'present'....(it) attempts to reveal the temporality and specificity of walking practices by accompanying people on their journeys and asking them to narrate their experiences ${ }^{7}$

This approach seems to have a particular utility in disability studies, where the static interview as a qualitative tool suffers for a variety of reasons. This is understood by occupational therapists who take the stance in assessment that understanding experience can best be achieved by engaging in everyday activities with the person. Ethnographers also understand that much of what people do in everyday activities is guided by dispositions, which can tell much about the desires, beliefs and expectations of that person, but can only be vaguely articulated, if at all. Bourdieu described the muteness that attends practices that are culturally embedded, using the concept of habitus. ${ }^{8}$ It is not enough to simply talk to the person, because their understanding has been so shaped by the habitus in which they are immersed. The static interview is part of a habitus that can pull the disabled person back into the field of medical discourse. It is all too easy for such interviews to evoke the illness narrative that has been previously co-constructed with health staff during clinical encounters. ${ }^{9}$ The disabled person is exposed at great length to such clinical encounters and Frank argues that this involves a process of "being colonized as medical territory and becoming a spectator to your own drama." 10 p59 For all these reasons the qualitative researcher learns to be suspicious of narratives that are smoothed through multiple iterations, losing significant layers of meaning in the process.

This study therefore set out to understand disability and injury in the context of the assemblage of activities that give meaning to the person. Mobility is one such essential activity and difficulty with walking is a defining feature of disability. Walking was felt to provide a particularly useful lens to examine the lived experience of participants. There is considerable literature describing mobility within both the medical and the social models, yet none of it speaks of the lived experience of the person with disability. In the medical model barriers to walking are usually described as factors intrinsic to the individual. For example, physical factors include joint or feet problems, neurological deficits; impaired balance, vision, or proprioception; cardiovascular and respiratory conditions; or urgency incontinence. Within the social model the constraints on mobility are described as extrinsic to the individual in terms of accessibility within social, economic and physical environments. Mobility for disabled people can be further affected by injury resulting from road traffic crashes, burns, falls, and accidents related to assistive devices. ${ }^{11}$ The World Report on Disability cites evidence of how people with disabilities can be at much greater risk of violence than those without disabilities. ${ }^{12}$

For the disabled person, ongoing mobility can be a private achievement of the disciplined body. It is laboured over consciously and usually studied in solitary depth. There are parallels with the embodied sense of the elite athlete, such as dancers, footballers or horse riders. ${ }^{13-16}$ Both the elite athlete and some disabled people push the body to its limit and injuries are a normalised occurrence, one that is expected and dealt with as it arises. Both live at the boundaries of what is possible with a particular body, in the knowledge that pain and injury is an ever present reality, creating undulating cycles of greater and lesser capacity. This involves a constant testing out of what the body is capable at strategic times within different contexts and for different purposes. What is different between these groups is how transitions for the elite athlete are negotiated in the context of a recognised social group. The vast majority of people with disability however must face the experience of transition without role models, and without established patterns of support and socialization. ${ }^{17}$ Irving describes it as a process whereby the bodies of people with disability are "inhabited, re-inhabited and re-evaluated over time."7

(c) The Internet Journal of Allied Health Sciences and Practice, 2014 
This study describes a moment where the bodies of people with pre-existing disability become 're-inhabited' as they learn to engage with walking. Walking is not something that can be taken for granted in this group and the fact of injury yet again removes the easy assumption of mobility. The focus of this paper is therefore on walking both as subject and as method: the interviewees talk about walking as they engage in the process of walking. The intention is to reflect on how walking as an interview method can add richness and depth to our understanding of walking in this group of people.

\section{METHODS}

This study is one component of a mixed method Prospective Outcomes of Injury Study (POIS)1. The quantitative component of the study involved extensive telephone interviews with a sample of 2856 injured people. The POIS study was conducted with a working age population (18 to 64 years) of those who were on the entitlement register of New Zealand's Accident Compensation Corporation (ACC). ACC is a unique form of no-fault compensation founded on the principle of community responsibility for all injuries, regardless of cause and POIS is the first major academic and independent study of outcomes from this system. The study received ethical approval from New Zealand's Multi-region Ethics Committee.

A maximum diversity sample of nineteen participants was purposively chosen from the quantitative sample for the qualitative study. This sample was then interviewed at six and twelve months after injury. These interviews were the basis of a paper identifying issues related to diagnosis following injury. ${ }^{25}$ From the group of nineteen participants the decision was made to further examine the experience of those who had a pre-injury disability, where disability was defined as a chronic condition diagnosed by a doctor and existing for one year before the injury. The methodology was extended to include walking as a way to gain an understanding of what injury meant to the disabled body. A revision was made to the ethics application and the participants signed a new consent form.

This group included four participants: two of whom had a brain injury at three and six years prior to the injury respectively (Matilda and John); one participant who had a degenerative neurological condition for over twenty years (Ronnie); the other who had a lifelong neurological condition (George). There was one female and three males and the participants ranged in age from 30 to 60 at the time of the first interview. Two of the participants were living in rural areas about 15 to $20 \mathrm{~km}$ from the nearest town; one of them lived in a small town and the other lived in a city. Pseudonyms are used throughout the findings and details that might be identifiable have been omitted or changed.

When returning for the walking interview each of the participants was phoned in advance to invite them to take part. It was explained that the interviewer wanted to understand what walking meant in their lives and that walking seemed the best way to get this understanding. They were invited to consider what helped and hindered their walking practice following the injury and to think of an everyday route that they would like to share with the interviewer. All of the participants readily agreed and seemed to have no problem understanding the format of the interview or the reasons for it. Interviews were guided by above focus and each interview was recorded and coded. The length of the walks varied between ten and ninety minutes. The primary focus of the researcher was as a participant observer, 'hanging out' ' within the context of a familiar activity for the respondent.

An iterative approach was used to analyse this data, developing themes from the codes identified. Coding was therefore carried out with this specific focus in mind and the themes generated reflected this focus. The information describing the background and ethos of the individual draws on the contextual detail that was available to the author as ethnographer. The intention of this paper is to convey a flavour of the rhythms and dynamics that attended walking as an integral part of interviewing. The stories are clustered around the individuals in order to illustrate how walking as an interview method provided a window to ways of understanding the embodied experience of disability.

\section{FINDINGS}

\section{Almost Dancing}

George was the only person in the study with a lifelong disability and conversations with him tended towards an impressive display of erudition about disability in general. He reflected liberally on the social model and his sense of how people with disability are stigmatised. His story was one that described a sense of living on the margins - pushing himself harder than everyone else and hiding this fact from others. By the time of this interview he recognised how personally destructive this refusal to recognise his own needs had become. The pain and fatigue that he was living with had become such that it was no longer possible to ignore his body. This realisation was joined with the insight that nobody could help him.

In the walking interview, he described how he had finally taken control of his own rehabilitation and had put himself through a six month programme of diet and fitness. This had involved a moment of revelation when he realised that he was capable of changing the way that he walked. His story was punctuated by sudden performances to demonstrate what he meant:

(c) The Internet Journal of Allied Health Sciences and Practice, 2014 
I was walking on a treadmill and walking like this. And through a glass window I could see by taking a fly spot on the window, I could track movements and I suddenly started seeing how up I went on each step (George)

Arriving at this level of self-consciousness was an important moment in a process of successfully learning how to walk with a greater sense of freedom. Throughout the walking interview he played with the thought that he felt well enough to be able to dance for the first time in his life:

It's hard to describe getting back these functions in my body and being able to do stuff, to be able to walk and move..... It's a feeling. My entire life is a dance. It's a balance and a movement and a negotiation. (George)

There were numerous points in the walking interview where George illustrated through action how he felt that he had improved since the injury. There was a situated element to these stories, which were often triggered by arriving at a particular place that triggered a specific memory. At one point during the walk he took off his orthotic shoes and he paced along the road in his socks to demonstrate a point. Then, as we walked up the hill back to his house' he was clearly tiring. He was still anxious however to emphasise how even this tiredness and capacity for endurance had been transformed:

By this bit I would be counting every one of the paint strips on the road, just to get there. There would be such focus... For the first time in my life I can look up and keep my head up. I have suddenly become aware that people walk around looking at things. It's to describe how many profound things have changed. (George)

Once we went inside, he wanted to demonstrate how low his blood pressure was because he was so fit. Instead he found that it was dangerously high. This was a sobering moment and the whole tone of the interview changed. The blood pressure reading reflected a particular truth that he had been emphasising since the first interview: how nobody could understand the difficulty of living within a disabled body. Even the thought of dancing in such a body now seemed incredibly dangerous:

To explain what the costs of dancing and those things, you've got no idea. You really don't, nobody can (George).

After a few moments of reflection, he turned from his computer to the piano to play and sing Leonard Cohen's "If it be your will". It was not a perfect performance, "I can't control my hands... they are slightly paralysed", but it was a very moving expression of what he was trying to achieve in his life. He started off communicating about the phenomenology of disability and ended up describing an internal dialogue about control and submission that was entirely human.

\section{Finding Balance}

Matilda was interviewed in her own home in a rural area. She had a confusing array of symptoms, including nerve damage caused by medical misadventure and a brain injury that was inadequately recognised. Her narrative was characterized by a baffled attempt to articulate what had happened, in the face of sense of betrayal by the medical system. She was acutely aware of how inarticulate and muddled her story appeared to others and she recognised that this was partly tied to the degree of fatigue that she experienced.

It seemed that she was finally going to get compensation when was placed on ACC's Serious Injury Service, set up to manage people with a permanent disability as a result of injury. Unfortunately this did not seem to have given her any of the expected extra entitlements she had hoped for. Instead, like George she began to find ways to take a lead in her own rehabilitation. She found a local class that was aimed at falls prevention in older people, and this helped her to address the lack of balance:

Who else is going to help me? l've got to do these things for myself. No one else is going to say, "Hey Matilda this is what you need to do". Even though l've asked for more balance exercises, it's never happened....l've been asking for so long, and I just found it myself (M3)

The walk that she chose to do wound around her extensive property, on paths of barely trampled wet grass going through thickets of gorse and broom. She was walking confidently when she was suddenly dazzled by shafts of sunlight coming through the branches of a tree. The effect on her was dramatic and unexpected. She nearly lost her balance, coming to a complete halt and unable to continue until she got her bearings.

My balance is based on what I can see that is still (M3) 
At this point, Matilda stopped trying to describe effects of the brain injury, because she could see I had understood. She began to tell more positive stories of how she had walked long distances from childhood and how she came to love hiking as an adult. All of this seemed very plausible as we walked a country road and she pointed to the hills she had climbed and the distances described in her stories. For the first time she started to tell her story as a self-reliant woman, strongly rooted in her local community and in relationships. As she walked she was able to describe with much greater clarity what each injury had contributed individually and together to her overall loss of capability. Illustrating the conversation with specific examples she described how her walking capacity had diminished because of pain after the medical misadventure. For a long time her marriage has lasted in spite of steadily deteriorating health:

We'd stop the car and walk at some new place or other. We just didn't go as far. We'd walk along the river. The stones were hard for me to walk on, but Dennis would just support me. He'd hold my arm. He'd ask how my leg was and if it started to get sore he'd say, right we'll go back now (Matilda)

Her marriage ended about three years after she had her brain injury, reportedly because neither of them could understand her behavior. She described some of this behavior: how she would become frantic, searching for things that she had lost:

He'd say, "Stop, you don't need to keep looking". But there was something in me that didn't know how to stop looking. And then l'd get to that nutty stage (Matilda).

Now, walking had become one of her most effective strategies for dealing with the cognitive and emotional effects of the brain injury. Walking became one of the ways to integrate her back with a sense of self that reflected who she was both now and in the past.

I still lose things, but I now know that after fifteen minutes I'm to stop looking... To make me stop, I get out of the house. Walking has become one of my strategies to deal with things that I can't deal with... (Matilda).

\section{Refusing to be a Victim}

Ronnie loved talking and was charmingly enthusiastic about almost everything except the question of how his so-called disability affected him. His interview was characterised by a sense of evasiveness, where he focused on the positive and changed the conversation whenever it came close to discussing his disability. He had a significant degenerative neurological condition, but had managed to continue to work as a high level volunteer.

When he did discuss his disability he tended to frame it in the context of whatever complementary therapy he was undertaking. Over the years there had been many and each contributed significantly to his understanding of himself and his way of understanding his condition. What seemed evident throughout the interview with Ronnie was how the experience of disability was mediated by whatever therapeutic modality he was engaged with at the time. Walking is of interest in his conversation primarily as a marker for how well a particular therapy has worked. In this case he felt that therapy had not only improved his relationships, but also his mobility:

They have identified what the conflict shock is about. It's no surprise that it is about anger...And since that time there has been an improvement in my left leg also (Ronnie).

His office was beside a large park, which seemed like an obvious place to go walking. Instead, his choice was to go to the back of the building, around a couple of car parks on the way to a cafe where he ordered a coffee which seemed contra-indicated by everything that he understood of his condition.

He did not enjoy walking, but even this short journey was enough to get much greater clarity about his ever present fear of falling. We were on our way back and in sight of the office when Ronnie suddenly and spontaneously broke into a few steps of a jog. It may have been the effect of the coffee, but it was a moment unlike any that had happened, because he was a person who so clearly did not engage at this physical level. Yet even then, as he described it, this was also an expression of his belief in the efficacy of psychotherapy as a way of controlling the effects of disability

I could run now (demonstrating).... Before, 3-4 months ago, I couldn't do that. Since I resolved some of these conflicts, now I can... The last time I was running was about 3 years ago (Ronnie).

(c) The Internet Journal of Allied Health Sciences and Practice, 2014 


\section{Living on the Edge of Menace}

John had a brain injury and his interview was a depressing litany of being taken advantage of, interspersed by inexplicable episodes of violence. He cared alone for his children, having been left by his wife and then his girlfriend. He was still employable, but over the course of time the kinds of jobs that he got steadily deteriorated. When he was not working he tended to be doing community service for one misdemeanour or other. This meant that he had even less time for managing the ordinary necessities around managing his health. His was a complex disability requiring ongoing medical intervention, but his life was so chaotic that it was, for example, impossible for him to keep appointments with his surgeon.

I arrived close to dusk, just as he was arriving home from work. He had clearly forgotten about the interview and since he had been out of the house since 5am and it seemed very demanding to ask him to go for a walk in the chill air. He insisted that we continue as planned and we walked briskly for a few blocks. When asked about how people at work responded to his disability, he said:

\section{A lot of people just think that l'm drugged or thick (John)}

The walking interview proceeded without much incident, though he was clearly very tired. He talked of feeling socially isolated and how he spent much of his time at the pub.

I was hanging out with a married woman. I've already had a black eye from the husband (John).

We were almost back at the house when he told a small story that changed the tenor of the interview and gave another perspective on the volatility in his life. He described how he responded to a neighbour who came to ask him to keep his hens locked up. At the time he was chopping wood and he reached for one of the hens and chopped off its head.

She comes through the gate and says "your hens have been in my garden"...I said "watch this, this bugger won't bug you anymore" and went Whack! Whack! (D3)

The story was intended to be funny and John seemed to have little insight into the volatility that was implicit in this behaviour. He was clearly tired and irritable and as we arrived back to his house he started banging on the back door and accusing his daughter of stealing his cigarettes. In those few moments an atmosphere of profound tension seemed palpable.

\section{DISCUSSION}

This paper describes walking as a method of interviewing that has the capacity to extend and challenge the more common static interview. Although the walking interview is an aspect of participant observation, it has not been used widely in disability research. Irving's work with participants with AIDS is a notable exception. ${ }^{7}$ He described beautifully the different rhythms and silences that arose around the walking interview compared to the interview where the person is sitting comfortably in their own chair. The walking interview has particular interest in the field of disability because of its inherent capacity to emphasise embodiment. In this paper walking was used both as a focus and a method. As a focus it was able to provide a narrow lens to determine whether the method deepened the understanding of this one aspect of the lived experience of the person with disability.

Affordance is a term borrowed from Gibson to consider what the activity lends itself to. ${ }^{21}$ Gibson defined affordances as all "action possibilities" latent in the environment, but also in relation to agents and therefore dependent on their capabilities. Each kind of activity has its own set of affordances, including a distinct way of relating to self and others through the medium of that activity. Scenery is passed and can become the focus of situated explanations and storytelling. Indeed much of the ethnography of walking has focussed on the ways that walking is associated with a sense of place. Indeed much of the ethnography of walking has focussed on the ways that walking is associated with a sense of place. It is possible to get a sense of the historical self that is inscribed in particular routes and hills prior to an injury; or the sense of threat experienced by the disabled person can be evoked by stories associated with the local neighbourhood. For example, Matilda's stories of hiking before she had injuries made much more sense when she could point to the hill tops where she had climbed; it was in the context of the way that the sun shuttered behind the branches that her problems with balance became objectified; George came to the hill where he was able to demonstrate his approach to walking;

Ingold describes as 'circumambulatory knowing' (p.331) the rhythms of thinking that can become associated with walking. ${ }^{22}$ This kind of situated cognition may be different for the person with disability who is forced to watch his feet and carefully note each step. Walking, for example, lends itself to a particular way of chatting about the physical reality of staying upright in the world: it is 
easy to talk about gait and balance when they are being demonstrated. George described the sense of freedom that he got from suddenly being able to walk with his head held high, where his walking began to verge on dancing.

The process of walking also offers a democratic method of communication that can unsettle the balance of 'biopower' described by Foucault, imposed on disabled bodies through their historical interactions with the medical system. ${ }^{23}$ For example, in this series of interviews the idea of dancing would have seemed out of place in an interview that took place from a sitting position, but it naturally arose in the context of walking in a much loved and familiar environment. Carpiano describes the greater equality afforded by the 'go-along' interview, as a difference between being a participant, rather than "simply a subject who is being interviewed." Where there is such participation, there is also the opportunity for spontaneity of gesture and expression: for example, breaking into a dance or a jog, or a sudden banging on the door. The seated interview on the other hand offers a degree of comfort and security that is the antithesis of such adventure.

Finally, the challenge of a physical activity renders the body visible in ways that do not occur if it remains seated. Generally, the habitual body is described as an absent body, and it only becomes present when it is hurt or damaged. ${ }^{24}$ This echoes the work of Turner who suggests that "it is important to pay attention to the question of performativity in order to grasp the role of embodiment in the phenomenology of pain and injury."14 The walking interview has a similar capacity to make the body present in ways that are not possible when seated. It is very easy to feel that there are no differences between people when both are seated comfortably; therefore the walking interview draws attention to the differences between the bodies of the interviewer and the participant. These differences can be seen in the rhythms of walking, in an awareness of how precarious balance is, in the sense of how fragile participation in the community is for those with cognitive and behaviour disabilities. A participant may be physically mobile, yet walking around a local community can betray a sense of alienation and loneliness that might not be readily admitted to amidst the comforts of home. John's volatility was unlikely to become evident without the trigger of movement and arriving at the place where a story hung in the air. Each of these interviews was attended by a sense of performance and the walk provided a stage that framed the participant's experience of disability. There was a denouement towards the end of each interview, often created by a reaction to fatigue. This would never have become visible from the comfort of the armchair.

A walking fieldwork approach has the potential to take both the interviewer and the participant beyond the well-worn grooves of generalising medical discourse that always threatens to alienate the disabled person from the particularity of their own story. The sedentary qualitative research interview carries echoes of medical interviews and has a tendency to generate similar patterns of discourse. This study suggests that the walking fieldwork has a role in interviewing where depth and alternative perspectives on the body are particularly sought. This study is positioned in the space between disability studies and medical anthropology. It makes a contribution by providing access to an embodied perspective of disability, which has so long been dissected by the medical gaze. The walking interview offers a method of making the body present to itself and to others and grants access to lived experiences that are ordinarily taken for granted. ${ }^{24}$ It is unlikely that walking is the only activity that would provide such access. As an occupational therapist, the first author is familiar with the range of affordances that are experienced through a range of activities in a therapeutic context. However, up to date this potential has not been drawn upon as a research method in its own right.

A limitation of this study is the lack of direct comparison between a sedentary interview and an interview with an embodied perspective. Although there were a range of interviews available from this particular group of respondents, the initial interviews did not focus on mobility per se. A future study might take a particular activity and examine how it was addressed from a sedentary compared to an embodied perspective. It is likely that discourse analysis would be the most suitable method to make such a comparison. A further limitation is the fact that the interviews were physically tiring for the respondents, and thus represented a burden on them. However, this limitation was partially resolved by the degree of control that the respondents had on the circumstances of the walk undertaken and the authenticity of the interview process. The study is also limited by the small size of the sample and the author is clearly informed by working as an occupational therapist. Small sample size and potential researcher bias should not be significant in qualitative research where there is no suggestion that the findings are to be generalised. Instead the reader is asked to consider whether the data meets criteria for transferability and can be considered relevant to other areas.

\section{ACKNOWLEDGEMENTS}

The study described in this paper was funded by an Accident Compensation Corporation Post-Doctoral Career Development Research Fellowship held by the author and by a Dean's Bequest Grant from the Dunedin School of Medicine. The Prospective Outcomes of Injury Study, from which the sample was drawn, was funded by the Health Research Council of New Zealand (2007-2013) and the Accident Compensation Corporation (2007-2010).The views and conclusions in this paper are the author's 
and may not reflect those of the funders. Beatrice Hale and Rebbecca Lilley are thanked for their helpful comments on earlier versions of this paper.

\section{REFERENCES}

1. Derrett S, Davie G, Ameratunga S, Wyeth E, Colhoun S, Wilson S, Samaranayaka A, Lilley R, Hokowhitu B, Hansen P, Langley J. (2011) Prospective Outcomes of Injury Study: Recruitment, and participant characteristics, health and disability status. Injury Prevention; 17(6): 415-418 [PMID: 21724742]

2. Wolcott HF. Writing up qualitative research. London: Sage; 2009.

3. Jones P, Griff B, Evans J, Gibbs H, Ricketts-Hein J. Exploring space and place with walking interviews. Journal of Research Practice. 2008;4(2):D2.Retrieved March 16, 2014, from http://irp.icaap.org/index.php//irp/article/view/150/161.

4. Kusenbach M. Street phenomenology: The go-along as ethnographic research tool. Ethnography. 2003;4(3):455-85.

5. Carpiano RM. Come take a walk with me: The "Go-Along" interview as a novel method for studying the implications of place for health and well-being Health \& Place. 2009;15(1):263-72. [PMID:18606557]

6. Anderson J. Talking whilst walking: A geographical archaeology of knowledge. Area. 2004;36(3):254-61.

7. Irving A. Life made strange: an Essay on the Re-inhabitation of Bodies and Landscapes. In: James W, Mills D, eds. The Qualities of Time: Anthropological Approaches. New York: Berg; 2005.

8. Bourdieu P. Distinction: a social critique of the judgement of taste. London: Routledge.; 1984.

9. Williams SJ. Chronic illness as biographical disruption or biographical disruption as chronic illness? reflections on a core concept. Sociology of Health and IIIness. 2000;22:40-67.

10. Frank A. "How Can They Act Like That?:" Clinicians and Patients as Characters in Each Other's Stories. Hastings Center Report. 2002;32(6):14-22. [PMID:12494860]

11. Xiang H, Chany A-M, Smith GA. Wheelchair related injuries treated in US emergency departments. Injury Prevention:Journal of the International Society for Child and Adolescent Injury Prevention. 2006;12:8-11.

12. World Health Organization. World Report on Disability. Geneva: World Health Organisation;2011.

13. Roderick M. Adding insult to injury: workplace injury in English professional football. Sociol Health III. 2006;28(1):76-97. [PMID:16509943]

14. Turner BS, Wainwright SP. Corps de Ballet: the case of the injured ballet dancer. Sociology of Health and Illness. 2003;25(4):269-88. [PMID:14498922]

15. Sparkes AC. Athletic identity: an achilles' heel to the survival of self. Qual Health Res. 1998;8(5):644-64. doi:10.1177/104973239800800506

16. Sparkes AC. Bodies, Narratives, Selves and Autobiography: The Example of Lance Armstrong. Journal of Sport and Social Issues. 2004;28(4):397-428. doi:10.1177/0193723504269907

17. Shakespeare T. Disability, Identity, Difference. In: Barnes CaM G, ed. Exploring the Divide. Leeds: The Disability Press.; 1996:94-113.

18. Desmond J. Embodying difference: Issues in dance and cultural studies. Cultural Critique. 1994;Winter:33-63.

19. Csordas T, ed Embodiment and experience. Cambridge: Cambridge University Press.; 1994.

20. Woodhouse O. The Woodhouse Report: Compensation for Personal Injury in New Zealand Wellington: Royal Commission of Inquiry; 1967.

21. Gibson JJ. The Ecological Approach to Visual Perception. Boston: Houghton-Mifflin; 1979.

22. Ingold T. Culture on the ground: the world perceived through the feet. Journal of Material Culture. 2004;9(3):315-40.

23. Foucault M. The History of Sexuality Vol.1: The Will to Knowledge. London: Penguin; 1998.

24. Leder D. The absent body. Chicago: University of Chicago Press; 1990.

25. Benner $P$. The tradition and skill of interpretive phenomenology in studying health, illness and caring practices. In: Benner P, ed. Interpretive phenomenology: embodiment, caring and ethics in health and illness. London: Sage publications; 1994.

26. Butler M, Derrett $\mathrm{S}$, Colhoun $\mathrm{S}$. The lived experience of patients with uncertain medical diagnosis following a serious injury: a qualitative study. Disability \& Rehabilitation. 2011;33(23-24):2247-54. [PMID: 21466278] 